\title{
Transport Service as a Component of the Tourism Industry Development of Ukraine
}

\author{
Hanna Brusiltseva ${ }^{1}$, and Olena Akhmedova ${ }^{1}$ \\ ${ }^{1}$ Simon Kuznets Kharkiv National University of Economics, Nauky av. 9-a, 61166 Kharkiv, Ukraine
}

\begin{abstract}
The research on the impact of transport services on the development of the tourism industry has been carried out. For the selection of the most significant factors of the transport infrastructure quality and tourist demand, which can affect the effectiveness of development indicators of a tourist destination, the correlation analysis methods have been used. To determine the development level of countries according to the quality and demand indicators of the transport services, the methods of cluster analysis have been used, which confirm the established hypotheses concerning the connection between the formed groups of factors and the development of tourist destination.
\end{abstract}

\section{Introduction}

Tourism sector is connected with the activity of more than 50 industries, the development of which generally contributes to the employment generation, economy diversification, cultural and natural potential preservation and development. It also increases the level of innovativeness of the national economy, promotes harmonization of relations between different countries. Thus, according to the Tourism and Travel Annual Report, in 2017 the contribution of the tourism sector was about USD 7.6 trillion that constituted $10.2 \%$ of GDP; the growth of international tourist flows allowed creating 292 million jobs [1]. In Ukraine, in 2017, tourism and related industries gave the budget UAH 40 billion, which is only $1.5 \%$ of GDP.

According to the results of the numerous studies, such a component as the transport service has a significant proportion in the structure of the tourist products cost. Thus, according to the Tourism Act of Ukraine, the tourism product includes a pre-designed tourist services complex that combines transportation services, accommodation services and other travel services that are not related to transportation and accommodation. As stated in various publications, the cost of the transport services can reach $60 \%$ or more of the tourist product value. The role of transport in the development of tourism is unconditional, as evidenced by the results of the Ukrainian and foreign scientists' researches and studies.

\section{Theoretical development and hypotheses formulation}

Transport infrastructure is very important to regional development and it is an important factor supporting economic activity. Transport becomes not only a means of transportation, ensuring accessibility of tourist resources, the factor of the industry development, but also acquires properties, functions of the tourist resource, attractor.

S. Page stated that transportation is one of the most important factors contributing to the success of the tourism industry [2].

\footnotetext{
*Corresponding author: anna.brusiltseva@hneu.net
} 
According to B. Lamb and S. Davidson, transportation is crucial in the tourism industry, since it directly connects the supply (production) and the demand (market) [3]. Transportation network and infrastructure is a significant factor affecting the success of tourism development [4]. D. Pearce argues that tourism growth is closely linked to advances in transport technology, which gradually facilitates access to the markets and destinations around the world [5]. Government plays a significant role in developing the infrastructure for tourist transportation [6].

T. Litman identified 12 transport factors that affect the accessibility of the destination, in particular: 1) transportation modes - the quality of transportation options, such as speed, comfort and safety; 2) transport network - density, communication routes or links between destinations; 3) fare or accessibility; 4) mobility - speed and distance, traffic performance or traveling time; 5) integration of the connections and modes into the transport system; 6) transport demand; 7) a user of information - the availability of reliable information about the possibilities of mobility and accessibility; 8) mobility substitutes - telecommunications and physical travel replacement services; 9) transport management; 10) factors of the land use; 11) priority of the tourism development; 12) the level of inaccessibility or isolation [7].

The results of Kenichi Shimamoto' researches in this area allow to identify the factors influencing the competitiveness of tourist destinations: the cost of experiencing the tourist destination; the disutility/utility of the tourist destination; the level of the destination's branding; the transportation fee; the costs related to traveling time; and the transportation means disutility/utility [8]. Jameel Khadaroo and Boopen Seetanah stated that traveling income, distance, and relative prices are important ingredients of their own respect in the tourism demand equation [6].

The factor of transportation is also taken into account while calculating the Global Competitiveness Index (GCI), the Travel and Tourism Competitiveness Index (TTCI), which contains two groups of indicators of the transport infrastructure development, namely, the infrastructure of air and land transport. Thus, the paper objective is to determine the key transport factors that significantly affect the tourism industry of a certain destination. In the result of the study, two groups of factors have been distinguished: the factors of the transport infrastructure and the factors of the tourists' transport demand. Thus, the following hypotheses have been proposed:

Hypothesis 1 . The development of a tourist destination depends on the quality of the transport infrastructure.

Hypothesis 2. The development of a tourist destination depends on tourist demand.

\section{Results}

Ukraine's transport infrastructure consists of different modes of transport. Each of them has its own specifics. In order to ensure the country's economy operation, all modes of transport should be interrelated and operate harmoniously. General transport network of Ukraine includes 21.0 thousand kilometres of railways, 159.4 thousand kilometres of highways with a hard surface, 1.6 thousand kilometres of operational river shipping routes with an access to the Azov and the Black Sea.

The research of the transport infrastructure factors should include the following indicators: the number of airports, the number of commercial aircrafts, the density of railways, the length of railways, the density of roads, the number of deaths on highways, etc.

While analysing the level of the transport infrastructure development according to the competitiveness index, it is necessary to note that in 2017, Ukraine took 79 place in terms of the development level of the aviation transport infrastructure and 81 place in terms of the development level of the land transport infrastructure. The main factors that negatively 
influenced the level of the transport infrastructure development are Quality of air transport infrastructure (102 position), Airport density (117), Quality of roads (132) [1].

Among the indicators, which characterize the demand for transport services, the number of passengers carried by the various modes of transport, revenues from the passenger transportation should be taken into account. In recent years, in Ukraine there has been a general tendency to reduce the passenger transportation market by almost all modes of transport that indicates a decrease in demand for transport services. Some positive changes are observed in the air transport sector. It is in place here to mention that the main mode of transport in Ukraine, which is in great demand among the consumers, is automotive. While there is a completely different situation in the world. Thus, according to UNWTO in 2017, slightly over half of all overnight visitors travelled to their destination by air (57\%), while the remainder travelled by surface transport $(45 \%)$ - whether by road $(37 \%)$, rail $(2 \%)$ or water $(4 \%)$ [9]. The trend over time has been for air transport to grow at a somewhat faster pace than surface transport, thus the share of air transport is gradually increasing.

To study the influence factors of tourism infrastructure and tourist demand on the tourist destination development, the following algorithm has been proposed.

Stage 1. The choice of the indicator of effectiveness of the tourist destination development.

Stage 2. The collection of information on the main indicators of tourism infrastructure and tourist demand that can affect the tourist destination development.

Stage 3. The calculation of the pair correlation coefficients between the indicator of effectiveness of the tourist destination development and the factors of influence, the determination of significant correlation coefficients according to the Student's criterion and clarification of the relationship nature between the relevant factors.

Stage 4. Grouping of the countries according to the level of the tourist destination development and transportation availability with the cluster analysis methods.

During the first stage, the tourist flows of European countries were selected as an indicator of effectiveness of the tourist destination development.

During the second and the third stages the indicators that have significant correlation coefficients (Table 1) were selected. Significance was estimated with the help of the Student's coefficient.

Table 1. Factors influencing the effectiveness of the tourist destination development that have significant correlation coefficients.

\begin{tabular}{|l|l|l|l|}
\hline \multicolumn{1}{|c|}{$\begin{array}{c}\text { Factors of transport } \\
\text { infrastructure quality }\end{array}$} & $\begin{array}{c}\text { The value of } \\
\text { correlation } \\
\text { coefficient }\end{array}$ & Factors of tourist demand & $\begin{array}{l}\text { The value of } \\
\text { correlation } \\
\text { coefficient }\end{array}$ \\
\hline $\begin{array}{l}\text { The commercial aircraft fleet, } \\
\text { number Var 1 }\end{array}$ & 0.58 & $\begin{array}{l}\text { Passenger transportation by } \\
\text { rail, number, Var 9 }\end{array}$ & 0.74 \\
\hline $\begin{array}{l}\text { The commercial aircraft fleet } \\
\text { with the useful lifetime less } \\
\text { than 5 years, number }\end{array}$ & 0.45 & $\begin{array}{l}\text { Passenger transportation by } \\
\text { air, number, Var 10 }\end{array}$ & 0.55 \\
\hline $\begin{array}{l}\text { Commercial airports (more than } \\
15,000 \text { passengers), number } \\
\text { Var 3 }\end{array}$ & 0.82 & $\begin{array}{l}\text { Revenues from passenger } \\
\text { transportation, mln. USD, } \\
\text { Var 11 }\end{array}$ & 0.65 \\
\hline $\begin{array}{l}\text { Air transport, registered take- } \\
\text { offs, number }\end{array}$ & 0.23 & $\begin{array}{l}\text { Transport expenses, mln. } \\
\text { USD, Var 12 }\end{array}$ & 0.57 \\
\hline $\begin{array}{l}\text { The length of railway tracks, } \\
\text { km Var 5 }\end{array}$ & 0.73 & & \\
\hline Deaths on highways, number & 0.33 & & \\
\hline
\end{tabular}


At the fourth stage, based on the desirable level of the study detalisation, three clusters of countries were identified: with the high, medium and low quality of transport infrastructure and factors of tourist demand.

Based on the iterative method of clustering k-means, the following cluster results have been obtained (Fig. 3, Fig. 4).

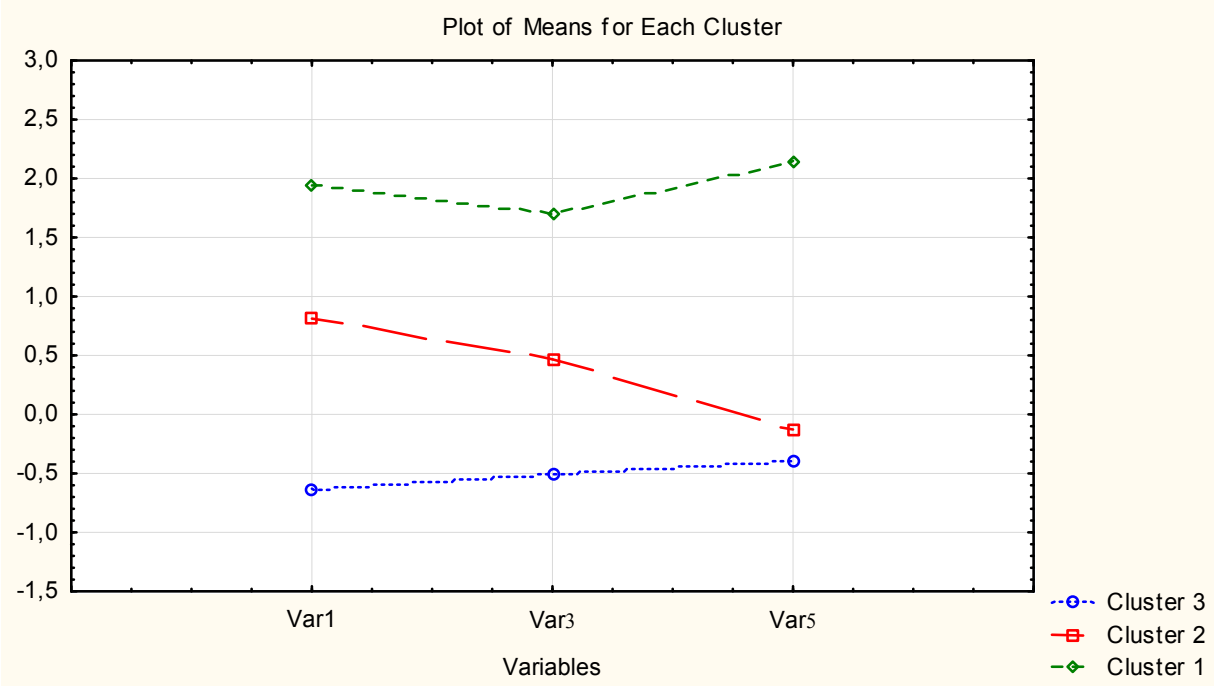

Fig. 3. Average means of transport infrastructure quality variables by clusters.

Source: Own research

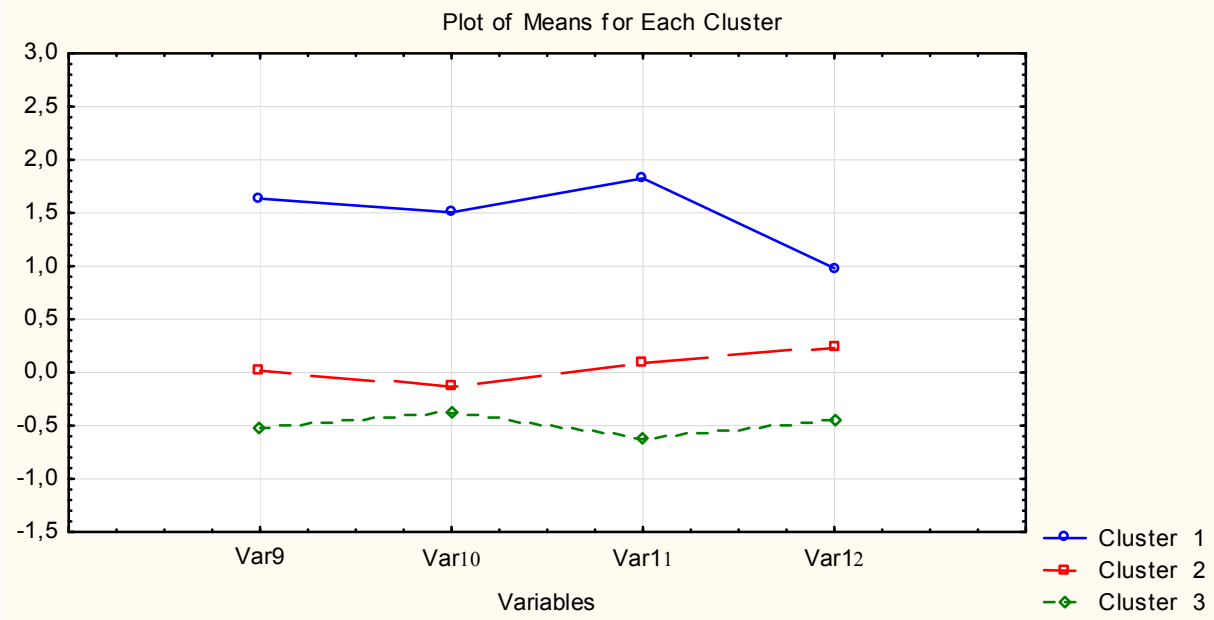

Fig. 4. Average means of tourist demand variables by clusters.

Source: Own research

The first cluster includes the countries with high indicators of the transport infrastructure quality and indicators that characterize tourist demand (Table 2). In addition, significant volumes of tourist flows characterize these countries.

Table 2. Members of Cluster 1 and Distances from Respective Cluster Centre. 


\begin{tabular}{|c|c|c|c|c|c|}
\hline \multicolumn{2}{|c|}{ Factors of transport infrastructure quality } & \multicolumn{3}{|c|}{ Factors of tourist demand } \\
\hline Case № & State & Distance & Case № & State & Distance \\
\hline C__1 & Germany & 1.707896 & C_1 & Germany & 0.845747 \\
\hline C_2 & France & 1.237087 & C_2 & France & 0.930060 \\
\hline C_4 & Spain & 1.631217 & C_4 & Spain & 0.668152 \\
\hline C_27 & UK & 1.376760 & C__27 & UK & 0.843107 \\
\hline C_31 & Turkey & 0.672639 & C_31 & Turkey & 0.906590 \\
\hline
\end{tabular}

The second cluster includes the countries with the average indicators of the transport infrastructure quality and indicators that characterize tourist demand (Table 3).

Table 3. Members of Cluster 2 and Distances from Respective Cluster Center.

\begin{tabular}{|c|c|c|c|c|c|}
\hline \multicolumn{2}{|c|}{ Factors of transport infrastructure quality } & \multicolumn{2}{c|}{ Factors of tourist demand } \\
\hline Case № & State & Distance & Case № & State & Distance \\
\hline C__3 & Italy & 0.783980 & C__3 & Italy & 0.404520 \\
\hline C_5 & Finland & 0.311705 & C_5 & Finland & 0.452581 \\
\hline C_6 & Austria & 0.326173 & C_11 & Greece & 0.681613 \\
\hline C_9 & Netherlands & 0.244367 & C_21 & Denmark & 0.287382 \\
\hline C_10 & Portugal & 0.493652 & C_24 & Poland & 0.787039 \\
\hline C_12 & Ireland & 0.681203 & C_26 & Sweden & 0.160468 \\
\hline C_24 & Poland & 1.070442 & C_28 & Switzerland & 0.167171 \\
\hline C_21 & Denmark & 0.332759 & C_24 & Poland & 0.787039 \\
\hline C_26 & Sweden & 1.257147 & & & \\
\hline C_28 & Switzerland & 0.224566 & & & \\
\hline
\end{tabular}

The third cluster includes the countries with the lower indicators of the transport infrastructure quality and indicators that characterize tourist demand (Table 4).

Table 4. Members of Cluster 2 and Distances from Respective Cluster Centre.

\begin{tabular}{|l|c|c|c|c|c|}
\hline \multicolumn{2}{|c|}{ Factors of transport infrastructure quality } & \multicolumn{3}{c|}{ Factors of tourist demand } \\
\hline Case № & Distance & Distance & $\begin{array}{c}\text { Case } \\
\text { № }\end{array}$ & Distance & Distance \\
\hline C__7 & Slovakia & 0.067171 & C__ & Slovakia & 0.067171 \\
\hline C_8 & Belorus & 0.164068 & C_8 & Belorus & 0.164068 \\
\hline C_11 & Greece & 0.156566 & C_9 & Netherlands & 0.156566 \\
\hline C_13 & Lithuania & 0.066646 & C_10 & Portugal & 0.066646 \\
\hline C_14 & Latvia & 0.069404 & C_12 & Ireland & 0.069404 \\
\hline C_15 & Estonia & 0.072214 & C_13 & Lithuania & 0.072214 \\
\hline C_16 & Slovenia & 0.069191 & C_14 & Latvia & 0.069191 \\
\hline C_17 & Moldova & 0.084050 & C_15 & Estonia & 0.084050 \\
\hline C_19 & Bulgaria & 0.068108 & C_16 & Slovenia & 0.068108 \\
\hline C_20 & Czech Republic & 0.188716 & C_17 & Moldova & 0.188716 \\
\hline C_22 & Croatia & 0.063330 & C_18 & Ukraine & 0.087582 \\
\hline C_23 & Hungary & 0.193069 & C_19 & Bulgaria & 0.063330 \\
\hline C_18 & Ukraine & 0.287382 & C_20 & Czech Republic & 0.193069 \\
\hline C_25 & Romania & 0.026193 & C_22 & Croatia & 0.026193 \\
\hline C_29 & Montenegro & 0.097160 & C_23 & Hungary & 0.097160 \\
\hline C_30 & Macedonia & 0.094974 & C_25 & Romania & 0.094974 \\
\hline & & & C_29 & Montenegro & 0.164068 \\
\hline & & & C_30 & Macedonia & 0.156566 \\
\hline
\end{tabular}

It should be noted that the structure of the second and the third clusters in the selected groups of factors is somewhat different. The reason for this is the close values of the 
indicators of both factors, namely, the length of the railways and the number of passengers transported by air transport. This is due to the relatively equal size of the territory of the countries included in the specified clusters. However, the overall results for Ukraine remain the same: in both cases, Ukraine is in the cluster with such countries as Moldova, Bulgaria, Hungary, Latvia, Lithuania, Belarus, Bulgaria, Estonia, Romania, etc.

\section{Conclusion}

Thus, the research on the impact of certain groups of transport infrastructure quality factors and tourist demand for transport services make it possible to claim their influence on the tourist destination development. In addition, the cluster groups obtained on the basis of these indicators confirm the hypotheses established in the research.

Nowadays the transport sector of Ukraine as a whole satisfies only the basic needs of the population and the economy in the volume of traffic, but not in the quality, which also creates significant obstacles to the development of domestic tourism. The current state of the transport industry does not fully meet the requirements of effective implementation of the European integration course of Ukraine and the integration of the national transport network into the Trans-European transport network.

According to the Association Agreement with the EU [10], it is necessary to increase the efficiency and competitiveness of the transport sector, primarily by improving the legal mechanism of public-private partnership, strengthening the interaction between the public and private sectors, state authorities and local self-government bodies, carrying out the necessary reforms through coordinated initiatives of the state politics. The implementation of the appropriate measures should provide a solid basis for the sustainable development of the transport industry and create a free and competitive market for tourist services.

\section{References}

1. The Travel \& Tourism Competitiveness Report 2017. Available at: https://www.weforum.org/reports/the-travel-tourism-competitiveness-report-2017

2. Page S. Transport and Tourism. Global Perspectives. Harlow: Pearson Prentice Hall, 447 (2009)

3. Lamb B., Davidson S. Tourism and Transportation in Ontario, Canada: A Vital Link. In Practicing Responsible Tourism: International Case Studies in Tourism Planning, Policy and Development. (1996)

4. Prideaux B. The role of the transport system in destination development. Tourism Management, 21(1), 53-63, (2000)

5. Lohmann G., Pearce D. Tourism and transport relationships: the suppliers' perspective in gateway destinations in New Zealand. Asia Pacific Journal of Tourism Research, 17(1), 14-29, (2012)

6. Khadarooa J., Seetanah B. The role of transport infrastructure in international tourism development: A gravity model approach. Tour. Management, 29, 831-840, (2008)

7. Litman T. "The New Transportation Planning Paradigm," ITE Journal (www.ite.org), 83, June, pp. 20-28; 2013 Available at https://www.vtpi.org/paradigm.pdf.

8. Shimamoto K. The Factors that Influence the Boundary Between the Markets of Competing Tourist. Destinations Tourism and Hospitality Management, 24(1), 1-12, (2018)

9. UNWTO Tourism Highlights: 2018 Edition. Available at: https://www.eunwto.org/doi/pdf/10.18111/9789284419876

10. Association Agreement between the European Union and Ukraine. Available at: https://www.kmu.gov.ua/en/yevropejska-integraciya/ugoda-pro-asociacyu 